\title{
Analysis on enterprise logistics management performance evaluation system
}

\author{
Jing Wen \\ Yellow River Conservancy Technical Institute, Kaifeng Henan, 475004, China
}

Keywords:Enterprise logistics management, Performance evaluation system.

\begin{abstract}
With the constant development of Chinese economy, development patterns in different industries and fields have formed into a united entirety linking to each other, especially when logistics industry is entering into a high-speed development era, more and more enterprise managers have realized the promoting effect of logistics construction management for the whole industry development. But currently there exist a lot of issues in the interior management and performance evaluation system in Chinese logistics field. The author has combined with many years' working practice experience to discuss the operation of enterprise logistics management performance evaluation system, and proposed effective countermeasures for reference.
\end{abstract}

\section{Introduction}

In the process of enterprise logistics management, enterprise logistics management performance evaluation system has played a very important supervision and promotion effect. Manger inside enterprise should combine their own operation situation to establish completed enterprise logistics management performance evaluation system, and start from multiple aspects of effectiveness, risks, cost and customer management so as to achieve the comprehensive evaluation and supervision on performance. With the promotion of Chinese marketization, a lot of Chinese logistics managers have had full understanding of the effect of enterprise logistics management performance evaluation system. But as a whole, their execution ability is relevantly low. How to enhance the establishment and implementation of enterprise logistics management performance evaluation system and how to improve the operating indicator in different aspects are problems for each manager to think and solve.

\section{Current status of Chinese enterprise logistics management performance evaluation system}

China's logistics enterprises emerge during the process of major industry development, and evolves with the fierce competition in social market. More and more logistics enterprises have had good development momentum. Each logistics enterprises have improved their market influence and competitiveness by their own practical production effectiveness. During the process of operation and management, enterprise manger have made comprehensive measurements of enterprise cost, effectiveness, and customer satisfaction, and finally formulate a complete enterprise logistics management performance evaluation system and realize the goal of more scientific management on enterprise. But it should be noted that, China's logistics enterprises are still in big gap with advanced countries' logistics enterprises. View from the current development status of China's logistics enterprises, many enterprise have made efforts in improving logistics effectiveness, and reduce costs, but imperfect in improving customer satisfaction and logistics enterprise image ${ }^{[1]}$. Thus, establishing a complete enterprise logistics management performance evaluation system has a very important effect. 


\section{Performance evaluation contents are not comprehensive}

Logistics enterprises' core competitiveness and the intangible assets, have actually influenced greatly on enterprises and during the process of industry competition and development. Relevant enterprise logistics management performance evaluation system construction has hardly valued the production and usage of intangible assets, or without comprehensive contents for the reference of specific performance evaluation operation. So a lot of enterprise logistics cultural values and logistics image, and customer contents are easily ignored by managers. Once loosening the evaluation on intangible assets and ignoring logistics operation, it will definitely cause great impact on enterprise logistics management and development especially managers cannot specifically refer to the enterprise current logistics management status and market development level during their operation material reference process.

\section{Performance evaluation standards are not unified}

Enterprise as a complete operation collective must have a sound and completed performance evaluation and unified evaluation standard. But currently, there exist no unified performance evaluation standard in China's a lot of logistics enterprises for reference and evaluation, and lack unified standard. Some different evaluation standards exist in the same or different department, which has caused a lot of trouble for enterprise logistics performance evaluation work, and harmful for the unity and harmony between enterprise working staffs.

\section{Hisroic cost compilation lacks reasonability}

In the process of constructing enterprise logistics management performance evaluation system, a lot of enterprises will be influenced by previous logistics management and performance data so as not to achieve the overall consideration, thus cannot really reflect the contents of enterprise economic activities or scientifically predict the future development direction and target of the enterprise. In addition, relevant weighted index setting will shift without reasonability. In enterprise logistics management performance evaluation work, the object is the leadership and management staffs in the enterprise. But disunity of standard and lack of reasonability of compilation will lead to the shortage of authenticity and objectivity of performance evaluation work so as to reduce working efficiency combining complex benefits.

\section{Principles of establishing enterprise logistics management performance evaluation system Economcal principle}

During the process of logistics management performance evaluation, participating enterprise should comprehensively consider cost and other factors according to the logistics operation condition, and the working load involved shall be in positive proportion with enterprise operation scale as the unconformity between performance evaluation workload with enterprise operation scale will produce more operation costs. Different evaluation indicators should be controlled effectively during evaluation together with actively referring to foreign advanced logistics enterprise' experience and advantages,, combined with the practical development for construction performance evaluation system, in accordance with economical principle and really control the evaluation cost within a reasonable scope of enterprise operation, and prevent the enterprise not working due to waste.

\section{Objectivity principle}

Objectivity principle is also one of important principles during constructing enterprise logistics management performance evaluation system. During this process, enterprise managers should refer to materials and data information from different aspects as important basis as performance evaluation, and try to reduce the intervention from exterior human factors and guarantee the justice and fairness of performance evaluation work and system construction and implementation, so as to provide effective referential basis for logistics enterprise managers in an objective evaluation form ${ }^{[3]}$. 


\section{Entirity principle}

This is a very critical principle requiring enterprise logistics management performance evaluation system to be implemented to individuals in different department for independent performance evaluation. But all staffs inside enterprises are participating individuals to carry out work following the evaluation system. Thus the entirety system could be the precondition of establishing and operating enterprise logistics management performance evaluation system. ${ }^{[4]}$. From another perspective, market enterprise is an independent entirety, so enterprise logistics management performance evaluation must evaluate the market subject so as to integrate the evaluation condition inside enterprise management departments and connect the logistics operation status in each procedure, and reflect the enterprise actual development. The proposal of this principle is related with the entirety of things' development in philosophy, thus enterprise operators should measure and promote the enterprise development from a whole aspect.

\section{Comparability principle}

Comparability principle mainly means that enterprises make vertical and crosswise comparison such as the comparison between domestic and foreign logistics cooperation performance evaluation data, through analyzing detailed data in performance evaluation and the information data integration in the operation process, to figure out potential problems and development gaps in its own operation process so as to refer to experience and methods of other enterprises, and then make longitude comparison between enterprise performance data with the previous data for a comprehensive understanding of enterprise own development status and clear understanding of the future development trend.

\section{Operability principle}

This principle decides whether enterprise logistics management performance evaluation work can be conducted smoothly. As a whole, enterprise logistics management performance evaluation system is a complex process involving data information and theoretical knowledge in various fields, thus setting different requirements for working staffs for relevant operation. Establishment and perfection of performance evaluation system means that more indicators should be completed which requires managers to comprehensively understand the conditions in different domains and carry out field investigation for obtaining updated effective data information so as to guide the establishment of performance evaluation system. Thus, before evaluation, the operability of enterprise logistics management performance evaluation system must be guaranteed. Also it is necessary to control the application difficulty degree by closely combining with enterprise own operation condition ${ }^{[5]}$.

\section{Qualitative and quantitive combined principle}

Qualitative and quantitive closely combined principle means that enterprise logistics management performance evaluation system construction should be regarded as an entirety in essence, fully considering its comprehensiveness ${ }^{[6]}$.A lot of large-scale enterprises have a complicated daily operation structure and process, thus enterprise logistics management performance evaluation will relate to many contents and have a lot of problems. Some are obvious and can be confirmed through relevant data such as enterprise cost and profits. But some data require to be objectively and comprehensively analyzed such as customer's accepting degree of enterprise culture and operating mode, and their understanding of enterprise cultural construction, etc. Thus it is necessary to closely stick to qualitative and quantitive combined principle for a comprehensive evaluation of performance [7] 


\section{Discussion on related contents of enterprise logistics management performance evaluation system}

\section{Cost index}

In enterprise logistics management performance evaluation system, partial cost index cannot be ignored such as transportation loading charges, packaging charges, purchasing charges, warehouse charges, and processing charges, etc. All of these constitute to cost index, thus enterprises should constantly perfect logistics data collecting system and make comprehensive analysis and conclusion of accounting information such as to comprehensively know salary cost, and then to refine salary accounting entry, for professional categorization treatment, and distribute salary expenditures to different cost system in different logistics stages.

\section{Efficiency index}

It is known to all that, there exist close connection between logistics efficiency, cost and logistics quantity. Relevant indicators include security rate, loss rate, and completion rate. Working staffs must control reasonably so as to improve the overall management efficiency. Procedures in logistics enterprises roughly include transportation and handling, purchasing, packaging, circulation and processing. Close connection between each procedure must be completed and working staffs must pay attention risks hidden in the connection. Logistics enterprises are sure to have different risks during daily management and operation but detailed risk evaluation can hardly be quantized, thus enterprise should do risk probability occurring, evaluating and description work and prevent the collision risk between inspection staffs, purchasing staffs, and financial staffs involved for the sake of interest, and clarify the transporting errors, stagnation and serious road condition and other risks existing in the transportation process.

\section{Customer satisfaction index}

It is very important for establishing enterprise logistics management performance evaluation system. In current market-oriented development trend, customer satisfaction is directly related to logistics management level. Satisfaction include the timeliness ratio of customer possession, obtaining ratio, accuracy ratio and completeness ratio. Only paying attention to customer satisfaction and dealing with logistics relationship with this as the goal, Logistics enterprise managers can better complete the enterprise logistics management performance evaluation indexes and reduce customer complaints to the minimum and improve customer's satisfaction of logistics work.

\section{Specific implementation of logistics performance evaluation system}

\section{Enterprise managers should pay great attention to logistics management performance evaluation system construction}

With the support of enterprise culture during development process, logistics enterprise must further confirm corporate culture and deepen the connotation and transmission can they establish staff's cost management thinking and have deeper understanding of risk management and apply to practical work so as to help enterprise to achieve economic benefits and social benefits. Thus enterprise managers must pay great attention to enterprise logistics management performance evaluation system construction and transmit to employees as a habit in the work, closely combine logistics management with human resource management, and encourage employees' mutual monitoring and urging to carry out work smoothly.

\section{Accelerate to construct logistics data collecting system}

To establish a sound data collecting system, logistics enterprise must start from cost, risk, customer satisfaction and working efficiency to establish a flexible, responsive data collecting system and pay attention to staff allocation, supply materials timely so as to satisfy market and customer demands ${ }^{[8]}$. 
Specifically, reduce cost and inventory so that funds can be turned over and used timely to improve efficiency and speed.

\section{Establish scientific and effective budge management}

Confirm the planning of logistics cost calculation in advance, and confirm different procedures of logistics management according to enterprise own operation condition so as to form a united entirety and incorporate suppliers and customer information into the system. Fully consider contents involving budge management such as logistics efficiency budge management, logistics risk expectation management, so as to formulate middle and long term management strategies and guarantee logistics enterprise cost allocation to maintain the best operating state. In addition, actively guide logistics management into the international standard road, introduce foreign advanced logistics management concepts and combine with its own operating features to formulate effective cost management measures, control logistics costs and create a platform for constructing enterprise logistics management performance evaluation system.

\section{Conclusion}

To sum up, logistics is one of major methods for enterprise development and expansion. Good enterprise will surely establish a completed enterprise logistics management performance evaluation system. Thus enterprise managers should pay attention to various indexes related to enterprise development, strengthen management and execution so as to help enterprise's stable development under the protection of enterprise logistics management performance evaluation system.

\section{Reference}

[1] Li Yanbin. Studies on the third party logistics enterprise CRM performance evaluation system, Southwestern University of Finance and Economics,2014, 12(11):11-16.

[2] Jiang Ming. Studies on the third party logistics enterprise performance evaluation system, Northern Economy,2011, 12(4):52-53.

[3] Wan Xian. Discussion on enterprise logistics management performance evaluation system, Intelligent City, 2015,12(2):309.

[4] Wang Yong, Yang Wenhui. Discussion on enterprise logistics management performance evaluation system, Business Studies,2013,31(4):163-164.

[5] Sui Yanrui. Studies on enterprise logistics management performance evaluation system, Researches on Urban Construction Theory (Electronic Edition), 2015,31(29):1449-1450.

[6] Yang Junfeng. Studies based on management effectiveness of enterprise logistics management performance evaluation, Logistics Technology,2014,33(11):240-241.

[7] Liu Haibin. Construction of enterprise logistics management performance evaluation system, Enterprise Reform and Management,2016,5(2-):70.

[8] Shen Yijuan. Analysis on enterprise logistics management performance evaluation system, Market Modernization,2016,14(821):33-34. 